\title{
Malnutrition Affects Cholesterol Paradox in Coronary Artery Disease: a 41,229 Chinese Cohort Study
}

\section{Bo Wang}

Guangdong Cardiovascular Institute

Jin Liu

Guangdong Cardiovascular Institute

\section{Shiqun Chen}

Guangdong Cardiovascular Institute

\section{Ming Ying}

Guangdong Cardiovascular Institute

\section{Guanzhong Chen}

South China University of Technology

\section{Liwei Liu}

Southern Medical University

\section{Zhubin Lun}

Guangdong Medical University

\section{Huanqiang Li}

Guangdong Cardiovascular Institute Haozhang Huang

Southern Medical University

\section{Qiang Li}

Guangdong Cardiovascular Institute

\section{Yaren $\mathrm{Yu}$}

First People's Hospital of Foshan

\section{Mengfei Lin}

Maoming People's Hospital

\section{Wen Wei}

Longyan First Hospital

\section{Zhidong Huang}

Guangdong Cardiovascular Institute

\section{Yongquan Yang}

Guangdong Cardiovascular Institute

Jiyan Chen 
Guangdong Cardiovascular Institute

\section{Ning Tan}

Guangdong Cardiovascular Institute

\section{Yong Liu ( $\nabla$ liuyong@gdph.org.cn )}

Guangdong Provincial People's Hospital https://orcid.org/0000-0003-2224-4885

\section{Research Article}

Keywords: Low density lipoprotein cholesterol, Coronary artery disease, Malnutrition, Long-term all-cause mortality

Posted Date: February 26th, 2021

DOl: https://doi.org/10.21203/rs.3.rs-266119/v1

License: (c) (1) This work is licensed under a Creative Commons Attribution 4.0 International License. Read Full License

Version of Record: A version of this preprint was published at Lipids in Health and Disease on April 19th, 2021. See the published version at https://doi.org/10.1186/s12944-021-01460-6. 


\section{Abstract}

Background: Several studies found that baseline low LDL-C concentration was associated with poor prognosis in patients with acute coronary syndrome (ACS), which was called "cholesterol paradox". Low LDL-C concentration may reflect underlying malnutrition, which was strongly associated with increased mortality. We objected to investigate the cholesterol paradox in patients with CAD and the effects of malnutrition.

Method: A total of 41,229 CAD patients admitted to Guangdong Provincial People's Hospital in China were included in this study from January 2007 to December 2018, and divided into two groups (LDL-C < $1.8 \mathrm{mmol} / \mathrm{L}, \mathrm{n}=4,863 ; \mathrm{LDL}-\mathrm{C} \geq 1.8 \mathrm{mmol} / \mathrm{L}, \mathrm{n}=36,366)$. We used Kaplan-Meier method and Cox regression analyses to assess the association between LDL-C levels and long-term all-cause mortality and the effect of malnutrition.

Result: In this real-world cohort (mean age 62.94 years; $74.94 \%$ male), there were 5257 incidents of allcause death during a median follow-up of 5.20 years [Inter-quartile range (IQR): 3.05-7.78 years]. KaplanMeier analysis showed that low LDL-C levels were associated with worse prognosis. After adjusting for baseline confounders (e.g., age, sex and comorbidities, etc.), multivariate Cox regression analysis revealed that low LDL-C level $(<1.8 \mathrm{mmol} / \mathrm{L})$ was not significantly associated with all-cause mortality (adjusted HR, 1.04; 95\% Cl, 0.96-1.24). After adjustment of nutritional status, risk of all-cause mortality of patients with low LDL-C level decreased (adjusted HR, 0.90; 95\% Cl, 0.83-0.98). In the final multivariate Cox model, low LDL-C level was related to better prognosis (adjusted HR, 0.91; 95\% Cl, 0.84-0.99).

Conclusion: Our results demonstrate that the cholesterol paradox persisted in CAD patients, but disappeared after accounting for the effects of malnutrition.

\section{Introduction}

Elevated low density lipoprotein cholesterol (LDL-C) concentration constitutes a major risk factor for poor prognosis of coronary artery disease $[1,2]$. Recent studies found that low levels of LDL-C were paradoxically associated with poor prognosis in patients with ACS, which was called "cholesterol paradox"[3-7]. LDL-C concentration was highly correlated with total cholesterol level which is an indicator of nutritional status $[8,9]$. Meanwhile, malnutrition is common among patients with CAD and is strongly associated with increased long-term mortality $[10,11]$. Thus, low LDL-C level may represent underlying malnutrition, which was related to the paradox.

Several factors may account for the "cholesterol paradox", including higher proportion of elder patients and higher proportion of baseline comorbidities. However, current studies did not address the impact of malnutrition on the cholesterol paradox.

Therefore, we sought to investigate the association between baseline low LDL-C levels and long-term allcause mortality in patients with CAD, after considering the effects of malnutrition. 


\section{Method}

\section{Study design and participants}

The retrospective observational study was conducted in Guangdong Provincial People's Hospital, China (Clinicaltrials.gov NCT04407936) from January 2007 to December 2018. During this period, there were 88,938 patients underwent coronary angiography (CAG) and 59,667 patients were diagnosed as CAD. We excluded patients $<18$ years old $(n=19)$, prior myocardial infarction $(n=3,922)$, prior undergoing $P C I(n=$ $4,996)$, prior undergoing coronary artery bypass grafting $(n=328)$, cancer $(n=659)$, lacking LDL-C examination $(n=1,782)$ and missing follow-up information of mortality $(n=6,662)$. A total of 41,229 patients were eventually included in the study (Fig. 1). The study protocol was approved by the Ethics Committee of Guangdong Provincial People's Hospital (No. GDREC2019555H[R1]) and was conducted in accordance with the Declaration of Helsinki.

\section{Procedures}

The clinical data for each patient with CAD was extracted from the electronic Clinical Management System of the Guangdong Provincial People's Hospital. Baseline data was collected on demographic characteristics, coexisting conditions, laboratory tests, and medication at discharge. In all patients, blood samples except lipid profiles were collected at admission or before coronary angiography (CAG) and percutaneous coronary intervention ( $\mathrm{PCl})$. The lipid was measured by overnight fasting blood sample. $\mathrm{CAG} / \mathrm{PCl}$ was performed in accordance with the standard clinical practice guidelines[12-14]. Senior cardiologists were responsible for the data quality control and periodical data verification. The follow-up information was retrieved from Guangdong Public Security System.

\section{Clinical outcome and definition}

The primary endpoint was long-term all-cause mortality. CAD was confirmed by CAG and discriminated according to the 10th Revision Codes of the International Classification of Diseases. Comorbidities including acute myocardial infarction (AMI), diabetes mellitus, hypertension, atrial fibrillation, chronic obstructive pulmonary disease (COPD) and Congestive heart failure (CHF). CHF was defined as New York Heart Association (NYHA) class $>2$ or Killip class $>1$ [15]. The estimated glomerular filtration rate (eGFR) was calculated using Modification of Diet in Renal Disease (MDRD) formula and Chronic kidney disease (CKD) was defined as eGFR $\leq 60 \mathrm{~mL} / \mathrm{min} / 1.73 \mathrm{~m}^{2}$ [16-18]. Anemia was defined as hematocrit $<39 \%$ for men and hematocrit $<36 \%$ for women, according to the World Health Organization criteria [19]. Nutrition status was assessed by the Controlling Nutritional Status (CONUT) score, a screening tool for the nutritional status of hospitalized patients [8]. It was calculated by serum albumin, cholesterol, and total lymphocyte count. Different scores represent different nutrition status (0-1 is normal; $2-4$ is mild malnutrition; $5-8$ is moderate malnutrition; $9-12$ is severe malnutrition).

\section{Statistical analysis}


Patients were divided into two groups according to the concentration of LDL-C high LDL-C level ( $\geq$ $1.8 \mathrm{mmol} / \mathrm{L})$ and low $\mathrm{LDL}-\mathrm{C}$ level $(<1.8 \mathrm{mmol} / \mathrm{L})$. Where appropriate, descriptive statistics are reported as mean (SD), median (interquartile range [IQR]), or numbers and percentages. For continuous variables with normal distributions, independent sample student t-test was conducted. Categorical variables were tested using Pearson chi-square. The prognosis was analyzed by Kaplan-Meier method, and the probability of outcomes in the two groups was analyzed by the survival curve. Survival differences between two groups were compared by log-rank test. For the association between baseline levels of LDL-C and long-term allcause mortality, hazard ratios (HR) were calculated with the use of a Cox proportional-hazards model (with a HR of less than 1.00 indicating a reduced risk of events in patients with LDL-C levels $<1.8$ $\mathrm{mmol} / \mathrm{L}$ ). Baseline variables that were considered clinically relevant were entered into multivariate Cox proportional-hazards regression model. Variables for inclusion were carefully chosen, given the number of events available, to ensure parsimony of the final model. The following four models were sequentially constructed with or without adjustment for covariates: 1) unadjusted; 2) adjusted age $\geq 75$ years, sex and comorbidities including AMI, diabetes mellitus, hypertension, atrial fibrillation, COPD, CHF, CKD and anemia; 3 ) adjusted nutritional status (CONUT score); 4) adjusted all covariates. All data analysis was performed by R software, version 3.6.3 (R Foundation for Statistical Computing). All $p$ values $<0.05$ were considered statistically significant.

\section{Result}

\section{Clinical characteristics}

A total of 41,229 CAD patients were included in the study. The baseline clinical characteristics of patients are shown in Table 1. As expected, patients with LDL-C level $<1.8 \mathrm{mmol} / \mathrm{L}$ were older and more likely to develop comorbidities than those with LDL-C level $\geq 1.8 \mathrm{mmol} / \mathrm{L}$. Notably, the prevalence of malnutrition was particularly high in patients with low baseline LDL-C concentration (Fig. 2). 
Table 1

Baseline characteristics

Characteristic*

Overall

LDL-C $<1.8 \mathrm{mmol} / \mathrm{L}$

$(\mathrm{N}=41,229)$
$(\mathrm{N}=4,863)$
$\mathrm{LDL}-\mathrm{C} \geq 1.8 \mathrm{mmol} / \mathrm{L}$

$P$ value

$(\mathrm{N}=36,366)$

\section{Demographic characteristics}

\begin{tabular}{lllll} 
Age, year & $62.94(10.62)$ & $64.38(10.81)$ & $62.75(10.58)$ & $<0.001$ \\
\hline Age $\geq 75$ years, $\mathrm{n}(\%)$ & $6036(14.64)$ & $929(19.10)$ & $5107(14.04)$ & $<0.001$ \\
\hline Male, $\mathrm{n}(\%)$ & $30897(74.94)$ & $3725(76.60)$ & $27172(74.72)$ & 0.005
\end{tabular}

\section{Coexisting conditions}

\begin{tabular}{|c|c|c|c|c|}
\hline $\mathrm{PCl}, \mathrm{n}(\%)$ & $30415(73.77)$ & $3433(70.59)$ & 26982(74.20) & $<0.001$ \\
\hline AMI, n (\%) & $9182(22.27)$ & $805(16.55)$ & $8377(23.04)$ & $<0.001$ \\
\hline CHF, n (\%) & $3902(9.48)$ & $409(8.42)$ & $3493(9.62)$ & 0.008 \\
\hline Hypertension, n (\%) & $23217(56.31)$ & $3020(62.10)$ & 20197(55.54) & $<0.001$ \\
\hline Diabetes mellitus, n (\%) & 11097(26.92) & 1623(33.37) & $9474(26.05)$ & $<0.001$ \\
\hline CKD, n (\%) & $8635(21.91)$ & $1154(24.84)$ & $7481(21.52)$ & $<0.001$ \\
\hline Atrial fibrillation, n (\%) & $939(2.28)$ & $133(2.74)$ & $806(2.22)$ & 0.026 \\
\hline COPD, n (\%) & $348(0.84)$ & $54(1.11)$ & $294(0.81)$ & 0.038 \\
\hline Stroke, n (\%) & $2340(5.68)$ & $347(7.14)$ & 1993(5.48) & $<0.001$ \\
\hline Anemia, n (\%) & $12922(32.31)$ & $2079(43.98)$ & 10843(30.74) & $<0.001$ \\
\hline \multicolumn{5}{|l|}{ Laboratory examination } \\
\hline Hematocrit & $0.40(0.05)$ & $0.38(0.05)$ & $0.40(0.05)$ & $<0.001$ \\
\hline Lymphocyte, $10^{9} / \mathrm{L}$ & $1.94(0.71)$ & $1.95(0.71)$ & $1.83(0.69)$ & $<0.001$ \\
\hline Total cholesterol, $\mathrm{mmol} / \mathrm{L}$ & $4.60(1.21)$ & $4.78(1.13)$ & $3.24(0.91)$ & $<0.001$ \\
\hline $\mathrm{HDL}-\mathrm{C}, \mathrm{mmol} / \mathrm{L}$ & $1.00(0.26)$ & $1.01(0.26)$ & $0.93(0.30)$ & $<0.001$ \\
\hline LDL-C, mmol/L & $2.85(0.98)$ & $1.47(0.26)$ & $3.04(0.88)$ & $<0.001$ \\
\hline Triglyceride, $\mathrm{mmol} / \mathrm{L}$ & $1.67(1.23)$ & $1.67(1.09)$ & $1.68(1.96)$ & 0.304 \\
\hline
\end{tabular}

* Data are presented as the mean value (standard deviation), median [interquartile range] or number of participants (percentage).

Abbreviations: LDL-C, low-density lipoprotein cholesterol; PCI, percutaneous coronary intervention; $\mathrm{AMI}$, acute myocardial infarction; CHF, congestive heart failure; CKD, chronic kidney injury; COPD, chronic obstructive pulmonary disease; HDL-C, high-density lipoprotein cholesterol; RASi, renin angiotensin system inhibitor. 


\begin{tabular}{|c|c|c|c|c|}
\hline Characteristic* & $\begin{array}{l}\text { Overall } \\
(\mathrm{N}=41,229)\end{array}$ & $\begin{array}{l}\text { LDL-C }<1.8 \mathrm{mmol} / \mathrm{L} \\
(\mathrm{N}=4,863)\end{array}$ & $\begin{array}{l}\text { LDL-C } \geq 1.8 \mathrm{mmol} / \mathrm{L} \\
(\mathrm{N}=36,366)\end{array}$ & $P$ value \\
\hline Albumin, $\mathrm{g} / \mathrm{L}$ & $36.29(4.25)$ & $36.36(4.22)$ & $35.74(4.44)$ & $<0.001$ \\
\hline \multicolumn{5}{|l|}{ Medicine } \\
\hline RASi, n (\%) & 20082(49.58) & $2199(46.46)$ & 17883(49.99) & $<0.001$ \\
\hline ß-blocker, n (\%) & 32652(80.61) & $3776(79.78)$ & 28876(80.72) & 0.131 \\
\hline Statins, n (\%) & $38300(94.55)$ & 4396(92.88) & 33904(94.77) & $<0.001$ \\
\hline \multicolumn{5}{|l|}{ Events } \\
\hline All-cause death, n (\%) & $5257(12.75)$ & 778(16.00) & 4479(12.32) & $<0.001$ \\
\hline \multicolumn{5}{|c|}{$\begin{array}{l}\text { * Data are presented as the mean value (standard deviation), median [interquartile range] or number } \\
\text { of participants (percentage). }\end{array}$} \\
\hline \multicolumn{5}{|c|}{$\begin{array}{l}\text { Abbreviations: LDL-C, low-density lipoprotein cholesterol; PCl, percutaneous coronary intervention; } \\
\text { AMI, acute myocardial infarction; CHF, congestive heart failure; CKD, chronic kidney injury; COPD, } \\
\text { chronic obstructive pulmonary disease; HDL-C, high-density lipoprotein cholesterol; RASi, renin } \\
\text { angiotensin system inhibitor. }\end{array}$} \\
\hline
\end{tabular}

\section{Primary outcomes}

During a median follow-up period of 5.20 years (IQR, 3.05-7.78 years), the rates of all-cause mortality was $12.75 \%(n=5257)$. Kaplan-Meier analysis revealed that prognosis in patients with LDL-C level $<1.8$ $\mathrm{mmol} / \mathrm{L}$ was worse (Fig. 3). Cox regression analysis was performed to remove confounders to determine the difference in prognosis between patients with LDL-C level $<1.8 \mathrm{mmol} / \mathrm{L}$ and those with LDL-C level $\geq$ $1.8 \mathrm{mmol} / \mathrm{L}$ (Table 2). After adjusting for age, sex and comorbidities (model 2), patients with LDL-C level $<1.8 \mathrm{mmol} / \mathrm{L}$ had non-significant difference in long-term all-cause mortality (adjusted HR: $1.04,95 \% \mathrm{Cl}$ : 0.96 to 1.12, Fig. 4). However, after adjustment of nutritional status (model 3), patients with LDL-C level < $1.8 \mathrm{mmol} / \mathrm{L}$ had lower risks of long-term all-cause death (adjusted HR: 0.90, 95\% Cl: 0.83 to 0.98, Fig. 4). After adjustment for full covariates (model 4), patients with LDL-C level $<1.8 \mathrm{mmol} / \mathrm{L}$ also had lower longterm risks of all-cause death (adjusted HR: $0.91 ; 95 \% \mathrm{Cl}: 0.84$ to 0.99 , Fig. 4). Malnutrition was the most important confounder of the relationship between low levels of LDL-C and clinical outcomes (Table 2).

\section{Discussion}

To our knowledge, few studies investigated the association between baseline LDL-C levels and long-term all-cause mortality in patients with CAD. The main finding of the current study is that the worse prognosis of patients with low LDL-C $(<1.8 \mathrm{mmol} / \mathrm{L})$ is mainly mediated by their higher prevalence of malnutrition. Our study demonstrated that the cholesterol paradox also existed among people with CAD. After accounting for the marked differences in their age, sex and presenting comorbidities, the differences were 
not significant between patients with different LDL-C levels. After adjustment of malnutrition, CAD patients with low LDL-C showed low risk of long-term all-cause mortality.

Our study showed an inverse association between baseline LDL-C level and long-term outcomes in unadjusted analysis. The cholesterol paradox was also observed in other studies involving subgroups of CAD patients (e.g., ACS) [3-7], highlighting the impact of baseline confounders. Cho et al found that among patients with acute myocardial infarction (AMI), lower baseline LDL-C $(<1.8 \mathrm{mmol} / \mathrm{L})$ was associated with higher 1-year mortality before adjusting for baseline confounders [3]. In that study, age and rate of comorbidities decreased as LDL-C increased. In a Cox proportional-hazards model, LDL-C level was not an independent predictor in 1-year mortality, after adjusting for baseline confounders. Wang et al demonstrated that higher admission LDL-C level was associated with better in-hospital survival in patients with ACS in unadjusted analysis [4]. Similarly, the results suggest cholesterol paradox may due to other clinical characteristics. Reddy et al, Al-Mallah et al and Nakahashi et al demonstrated that lower baseline LDL-C level was associated with higher mortality before and after adjusting for baseline confounders[5-7]. All five studies attempted to explore the mechanisms behind the paradox by taking baseline confounding factors into account, which included demographic information and comorbidities. There are noteworthy similarities between our study and the five previous studies. First, these study groups were all patients with CAD. Second, the LDL-C levels were all the baseline values collected at admission. Third, after adjusting for baseline confounders (age, gender, comorbidity, etc.), decreased baseline LDL-C concentration was not associated with declined long-term mortality.

However, the influence of nutritional status was not considered in depth. According to available data from the five studies, patients with lower LDL-C also had lower plasma albumin and total cholesterol concentrations, which may reflect underlying malnutrition status. CONUT score was an efficient tool for early detection and continuous control of in-hospital undernutrition [8]. Low LDL-C level always combined malnutrition. In our study, prevalence of malnutrition was $56.30 \%, 51.75 \%$ and $90.30 \%$ in overall population, $\mathrm{LDL}-\mathrm{C} \geq 1.8 \mathrm{mmol} / \mathrm{L}$ group and $\mathrm{LDL}-\mathrm{C}<1.8 \mathrm{mmol} / \mathrm{L}$ group, respectively. The malnutrition rate of patients with low LDL-C level was much higher than that of patients with high LDL-C level. This was also observed in other studies, highlighting the importance of nutritional status [10,11]. Roubín et al's finding showed that in patients with ACS $38.5 \%, 10.4 \%$ and $0.9 \%$ patients were mildly, moderately and severely malnourished according to CONUT score, respectively [10]. Roubín et al and Wada et al found that nutritional status assessed by the CONUT score was significantly associated with long-term clinical outcomes in patients with CAD $[10,11]$.

There may be several possible explanations for the cholesterol paradox. First, a plausible explanation for the absence of a positive correlation between baseline LDL-C and long-term all-cause mortality before adjustment is that these patients have a higher proportion of elder people ( $\geq 75 y$ ears) and comorbidities according to baseline characteristics, which was associated with worse prognosis. Patients with LDL-C level $<1.8 \mathrm{mmol} / \mathrm{L}$ had significantly higher prevalence than those with LDL-C $\geq 1.8 \mathrm{mmol} / \mathrm{L}$ in patients aged $\geq 75$ years ( $19.10 \%$ vs. $14.04 \%$ ), diabetes mellitus ( $33.37 \%$ vs. $26.05 \%)$, anemia ( $43.18 \%$ vs. $30.30 \%)$ and atrial fibrillation ( $2.74 \%$ vs. $2.22 \%$ ). Additionally, the increased long-term mortality may result from 
basic diseases to some extent. It is well known that smokers have better survival after AMI (the smoker paradox) [20]. The smoker's paradox was explained by the younger age and fewer cardiovascular risk factors in smokers compared with nonsmokers. Also, several studies have previously reported that patients with higher BMI have better clinical outcomes after $\mathrm{PCl}$ (the obesity paradox) [21, 22]. Furthermore, recent studies have suggested that the mechanism of the obesity paradox may be related to confounders of baseline characteristics associated with survival [23-25]. Similarly, in our study, multivariate Cox regression analysis revealed that baseline LDL-C level was not an independent predictor of mortality after adjusting for age, sex and comorbidities. Second, patients with lower LDL-C level were at poorer nutritional status. Malnutrition, in particular, significantly affected prognosis. Compared with unadjusted model, the correlation between low LDL-C level and prognosis changed from negative to positive after adjustment of malnutrition. Previous study has found that low total cholesterol represents a biological marker for concurrent cachexia, malnutrition, cancer, and other chronic diseases with a proven adverse impact on survival[26]. Moreover, evidences are emerging that cholesterol is related to the regulation of immune cell function by improving their antitumor activity and activating immune signaling, which may provide novel insights into the role of cholesterol in the development of cancer[27-29]. Malnutrition has been singled out as the most common cause of secondary immunologic dysfunction [30]. Failure to recognize or to anticipate the development of malnutrition can allow the needless presence of nutrition-related immunodeficiency and proneness to infection, with morbidity and mortality increased. Hence, the cholesterol paradox in patients with CAD may be mainly associated with malnutrition.

All these findings strongly support the need for physicians to integrate in their daily practice the identification of malnutrition. This may improve the risk stratification and guide subsequent interventions of secondary prevention. The effect of malnutrition should be considered when LDL-C is used to assess the risk of poor prognosis in CAD patients. Clinicians should not let down their guard when they meet CAD patients with low LDL-C level. Malnutrition screening in patients with CAD might identify patients at high risk of adverse outcomes who might benefit from tailored secondary prevention programs with nutritional supplements to improve their prognosis.

The study was conducted at Guangdong Provincial People's Hospital which is the largest cardiovascular center in South China and the sample size was sizeable. However, there were some limitations among this analysis. First, this study was a retrospective single-center study. Second, a single value of LDL-C at admission was used, which made it difficult to assess the effect of changes in LDL-C level at follow-up on clinical outcomes. Therefore, the study focused on the clinical significance of initial LDL cholesterol level on clinical outcomes among patients with CAD.

\section{Conclusion}

The cholesterol paradox persists in patients with CAD. However, after removing the effect of malnutrition, low baseline LDL-C level $(<1.8 \mathrm{mmol} / \mathrm{L})$ was associated with decreased risk of long-term all-cause mortality. Our findings indicate that low LDL-C level on admission did not mean low risk of long-term all- 
cause mortality among CAD patients and low LDL-C level should be alerted that CAD patients probably had underlying malnutrition.

\section{Abbreviations}

LDL-C: low-density lipoprotein cholesterol; CAD: coronary artery disease; CAG: coronary angiography; PCI: percutaneous coronary intervention; AMI: previous acute myocardial infarction; CHF: congestive heart failure; CKD: chronic kidney disease; COPD: chronic obstructive pulmonary disease; HR: hazard ratio; $\mathrm{Cl}$ : confidence interval.

\section{Declarations}

\section{Acknowledgments}

We acknowledge Jingru Deng and Liangguang Meng in Guangdong Provincial Key Laboratory of Coronary Heart Disease Prevention for help in data extraction and verification.

\section{Authors' contributions}

$Y L, J L$ and SQC had full access to data and takes responsibility for the integrity and the accuracy of the data analysis. Concept and design: $\mathrm{JL}$ and BW. Acquisition, analysis, and interpretation of data: all authors. Data management: YQY. Drafting of the manuscript: BW, MY, GZC, LWL, ZBL, HQL, HZH, QL, YRY, MFL, WW and ZDH. Critical revision: YL, NT and JYC. Final approval to publish: YL and NT. The authors read and approved the final manuscript.

\section{Funding}

This study was supported by the National Natural Science Foundation of China (Grant No. 81670339 and Grant No. 81970311), Cardiovascular Research Foundation Project of the Chinese Medical Doctor Association (SCRFCMDA201216) and Beijing Lisheng Cardiovascular Health Foundation (LHJJ20141751).

\section{Availability of data and materials}

Not applicable at this stage. The datasets analyzed during the current study will be available from the corresponding author on reasonable request when the study is finished.

\section{Ethical approval}

This study was conducted in accordance with the Declaration of Helsinki and was approved by the Research Ethics Committee of Guangdong Provincial People's Hospital, Guangdong Academy of Medical Sciences (No. GDREC2019555H[R1]). This is a retrospective observational study and the informed consent to participate is not applicable. 


\section{Consent for publication}

Not Applicable.

\section{Competing interests}

The authors declare that they have no competing interests.

\section{References}

1. Mach F, Baigent C, Catapano AL, Koskinas KC, Casula M, Badimon L, et al. 2019 ESC/EAS Guidelines for the management of dyslipidaemias: lipid modification to reduce cardiovascular risk. Eur Heart J. 2020;41(1):111-88.

2. Baigent C, Blackwell L, Emberson J, Holland LE, Reith C, Bhala N, et al. Efficacy and safety of more intensive lowering of LDL cholesterol: a meta-analysis of data from 170,000 participants in 26 randomised trials. Lancet. 2010;376(9753):1670-81.

3. Cho KH, Jeong MH, Ahn Y, Kim YJ, Chae SC, Hong TJ, et al. Low-density lipoprotein cholesterol level in patients with acute myocardial infarction having percutaneous coronary intervention (the cholesterol paradox). Am J Cardiol. 2010;106(8):1061-8.

4. Wang TY, Newby LK, Chen AY, Mulgund J, Roe MT, Sonel AF, et al. Hypercholesterolemia paradox in relation to mortality in acute coronary syndrome. Clin Cardiol. 2009;32(9):E22-8.

5. Al-Mallah $\mathrm{MH}$, Hatahet $\mathrm{H}$, Cavalcante JL, Khanal S. Low admission LDL-cholesterol is associated with increased 3-year all-cause mortality in patients with non ST segment elevation myocardial infarction. Cardiol J. 2009;16(3):227-33.

6. Reddy VS, Bui QT, Jacobs JR, Begelman SM, Miller DP, French WJ. Relationship between serum lowdensity lipoprotein cholesterol and in-hospital mortality following acute myocardial infarction (the lipid paradox). Am J Cardiol. 2015;115(5):557-62.

7. Nakahashi T, Tada H, Sakata K, Yakuta Y, Tanaka Y, Nomura A, et al. Paradoxical impact of decreased low-density lipoprotein cholesterol level at baseline on the long-term prognosis in patients with acute coronary syndrome. Heart Vessels. 2018;33(7):695-705.

8. Ignacio de Ulíbarri J, González-Madroño A, de Villar NG, González P, González B, Mancha A, et al. CONUT: a tool for controlling nutritional status. First validation in a hospital population. Nutr Hosp. 2005;20(1):38-45.

9. Welsh C, Celis-Morales CA, Brown R, Mackay DF, Lewsey J, Mark PB, et al. Comparison of Conventional Lipoprotein Tests and Apolipoproteins in the Prediction of Cardiovascular Disease. Circulation. 2019;140(7):542-52.

10. Raposeiras Roubín S, Abu Assi E, Cespón Fernandez M, Barreiro Pardal C, Lizancos Castro A, Parada $\mathrm{JA}$, et al. Prevalence and Prognostic Significance of Malnutrition in Patients With Acute Coronary Syndrome. J Am Coll Cardiol. 2020;76(7):828-40. 
11. Wada H, Dohi T, Miyauchi K, Doi S, Konishi H, Naito R, et al. Prognostic impact of nutritional status assessed by the Controlling Nutritional Status score in patients with stable coronary artery disease undergoing percutaneous coronary intervention. Clin Res Cardiol. 2017;106(11):875-83.

12. Kushner FG, Hand M, Smith SC Jr, King SB 3rd, Anderson JL, Antman EM, et al. 2009 focused updates: ACC/AHA guidelines for the management of patients with ST-elevation myocardial infarction (updating the 2004 guideline and 2007 focused update) and ACC/AHA/SCAl guidelines on percutaneous coronary intervention (updating the 2005 guideline and 2007 focused update) a report of the American College of Cardiology Foundation/American Heart Association Task Force on Practice Guidelines. J Am Coll Cardiol. 2009;54(23):2205-41.

13. Jneid H, Anderson JL, Wright RS, Adams CD, Bridges CR, Casey DE Jr, et al. 2012 ACCF/AHA focused update of the guideline for the management of patients with unstable angina/non-ST-elevation myocardial infarction (updating the 2007 guideline and replacing the 2011 focused update): a report of the American College of Cardiology Foundation/American Heart Association Task Force on Practice Guidelines. J Am Coll Cardiol. 2012;60(7):645-81.

14. Levine GN, Bates ER, Blankenship JC, Bailey SR, Bittl JA, Cercek B, et al. 2015 ACC/AHA/SCAI Focused Update on Primary Percutaneous Coronary Intervention for Patients With ST-Elevation Myocardial Infarction: An Update of the 2011 ACCF/AHA/SCAI Guideline for Percutaneous Coronary Intervention and the 2013 ACCF/AHA Guideline for the Management of ST-Elevation Myocardial Infarction. J Am Coll Cardiol. 2016;67(10):1235-50.

15. Mehran R, Aymong ED, Nikolsky E, Lasic Z, lakovou I, Fahy M, et al. A simple risk score for prediction of contrast-induced nephropathy after percutaneous coronary intervention: development and initial validation. J Am Coll Cardiol. 2004;44(7):1393-9.

16. Levey AS, Bosch JP, Lewis JB, Greene T, Rogers N, Roth D. A more accurate method to estimate glomerular filtration rate from serum creatinine: a new prediction equation. Modification of Diet in Renal Disease Study Group. Ann Intern Med. 1999;130(6):461-70.

17. K/DOQI clinical. practice guidelines for chronic kidney disease: evaluation, classification, and stratification. Am J Kidney Dis. 2002;39(2 Suppl 1):1-266.

18. Manjunath G, Tighiouart H, Ibrahim H, MacLeod B, Salem DN, Griffith JL, et al. Level of kidney function as a risk factor for atherosclerotic cardiovascular outcomes in the community. J Am Coll Cardiol. 2003;41(1):47-55.

19. Nutritional anaemias. Report of a WHO scientific group. World Health Organ Tech Rep Ser. 1968;405:5-37.

20. Redfors B, Furer A, Selker HP, Thiele H, Patel MR, Chen S, et al. Effect of Smoking on Outcomes of Primary PCl in Patients With STEMI. J Am Coll Cardiol. 2020;75(15):1743-54.

21. Gruberg L, Weissman NJ, Waksman R, Fuchs S, Deible R, Pinnow EE, et al. The impact of obesity on the short-term and long-term outcomes after percutaneous coronary intervention: the obesity paradox? J Am Coll Cardiol. 2002;39(4):578-84. 
22. Mehta L, Devlin W, McCullough PA, O'Neill WW, Skelding KA, Stone GW, et al. Impact of body mass index on outcomes after percutaneous coronary intervention in patients with acute myocardial infarction. Am J Cardiol. 2007;99(7):906-10.

23. Zeller M, Steg PG, Ravisy J, Lorgis L, Laurent $Y$, Sicard P, et al. Relation between body mass index, waist circumference, and death after acute myocardial infarction. Circulation. 2008;118(5):482-90.

24. Nikolsky E, Stone GW, Grines CL, Cox DA, Garcia E, Tcheng JE, et al. Impact of body mass index on outcomes after primary angioplasty in acute myocardial infarction. Am Heart J. 2006;151(1):16875.

25. Kang WY, Jeong MH, Ahn YK, Kim JH, Chae SC, Kim YJ, et al. Obesity paradox in Korean patients undergoing primary percutaneous coronary intervention in ST-segment elevation myocardial infarction. J Cardiol. 2010;55(1):84-91.

26. Nakagomi A, Seino Y, Noma S, Kohashi K, Kosugi M, Kato K, et al. Relationships between the serum cholesterol levels, production of monocyte proinflammatory cytokines and long-term prognosis in patients with chronic heart failure. Intern Med. 2014;53(21):2415-24.

27. Míguez MJ, Rosenberg R, Burbano X, Malow R. Cholesterol as a Mediator of Alcohol-Induced Risks for Respiratory Disease Hospitalizations among People Living With HIV. J AIDS Clin Res. 2011;SuppI $1(1)$.

28. Yang W, Bai Y, Xiong Y, Zhang J, Chen S, Zheng X, et al. Potentiating the antitumour response of CD8(+) T cells by modulating cholesterol metabolism. Nature. 2016;531(7596):651-5.

29. Yasumasu T, Takahara K, Sadayasu T, Date H, Isozumi K, Kouzuma R, et al. Effect of plasma lipoproteins on natural killer cell activity in the elderly population. J Gerontol A Biol Sci Med Sci. 2003;58(6):561-5.

30. Cereda E, Pusani C, Limonta D, Vanotti A. The association of Geriatric Nutritional Risk Index and total lymphocyte count with short-term nutrition-related complications in institutionalised elderly. J Am Coll Nutr. 2008;27(3):406-13.

\section{Figures}


All patients underwent coronary angiography at

Guangdong Provincial People's Hospital from

January 2007 to December $2018(n=88,938)$.

Patients were diagnosed as coronary artery

disease $(n=59,667)$.

Exclusion criteria:

$(1)<18$ years old $(n=19)$;

(2) Prior myocardial infarction $(n=3,922)$;

(3) Prior underwent PCI $(n=4,996)$;

(4) Prior coronary Artery Bypass Grafting, $(n=328)$;

(5)Cancer $(\mathrm{n}=659)$;

(6)Lacking LDL-C examination $(n=1,782)$;

(7)Missing follow-up information of mortality $(n=6,662)$.

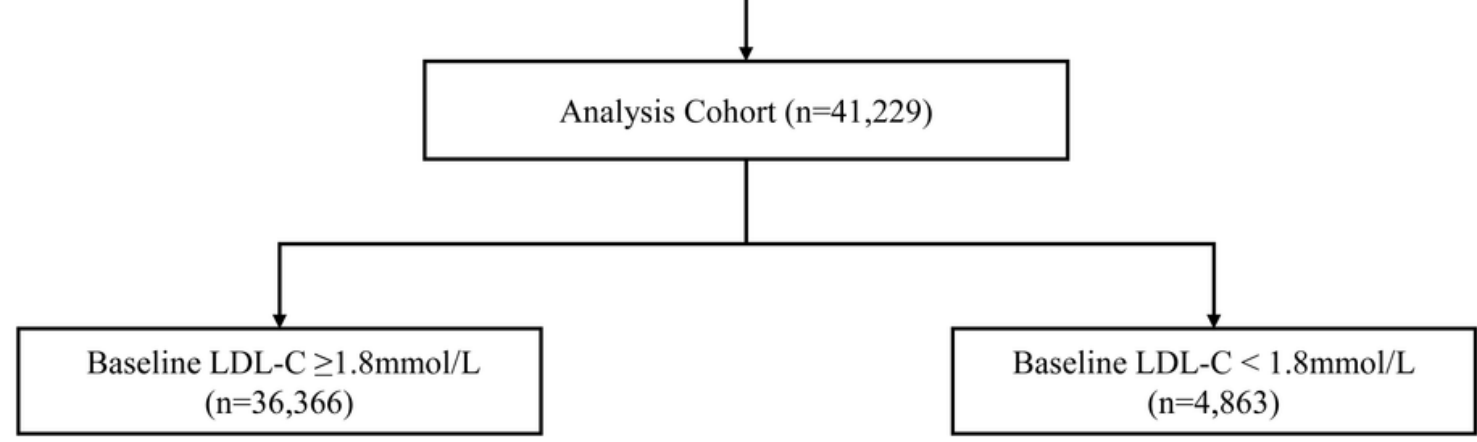

\section{Figure 1}

Study flow chart. 


\section{The proportion of nutritional status in both groups}

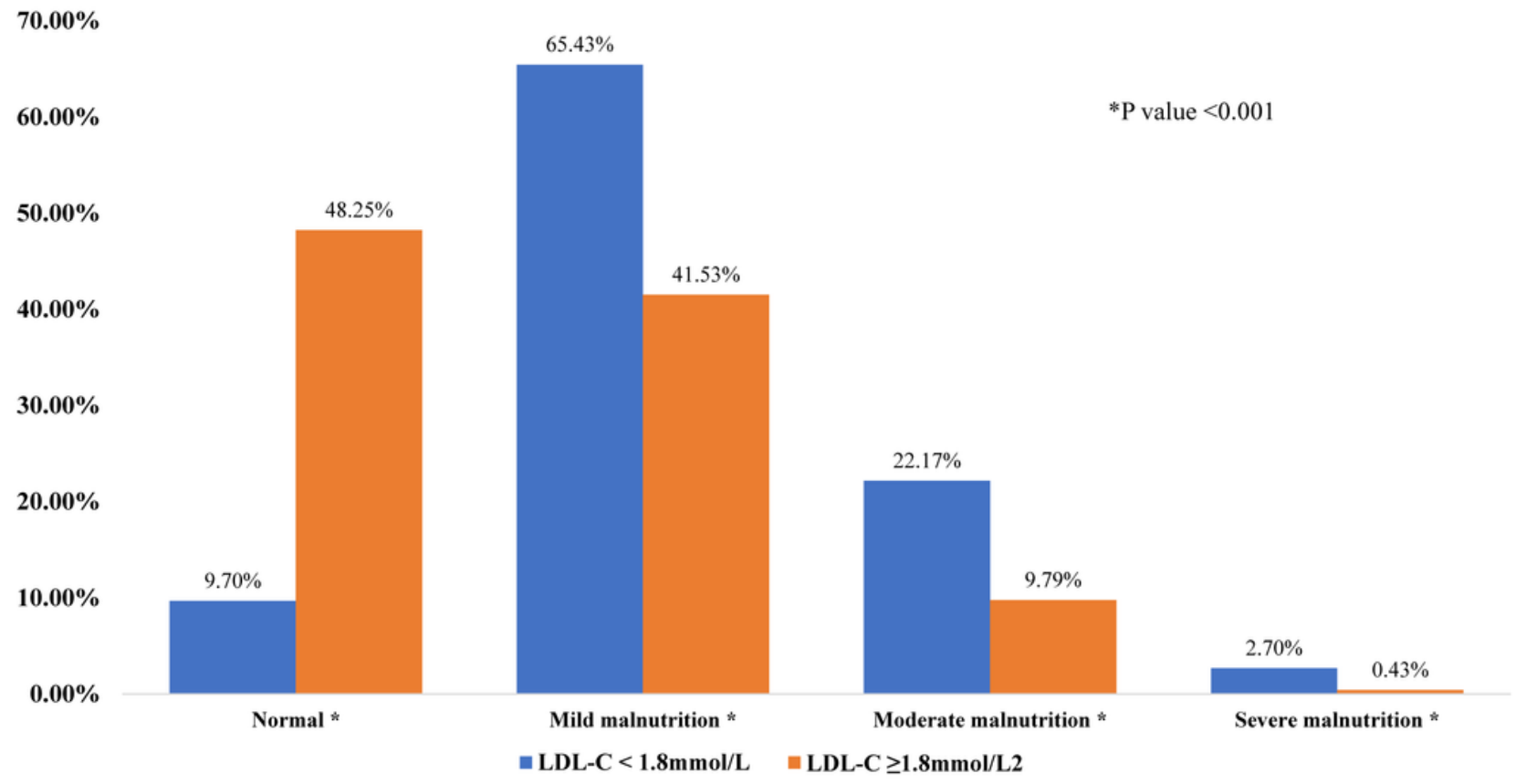

\section{Figure 2}

The proportion of nutritional status in LDL-C $<1.8 \mathrm{mmol} / \mathrm{L}$ group and LDL-C $\geq 1.8 \mathrm{mmol} / \mathrm{L}$ group.

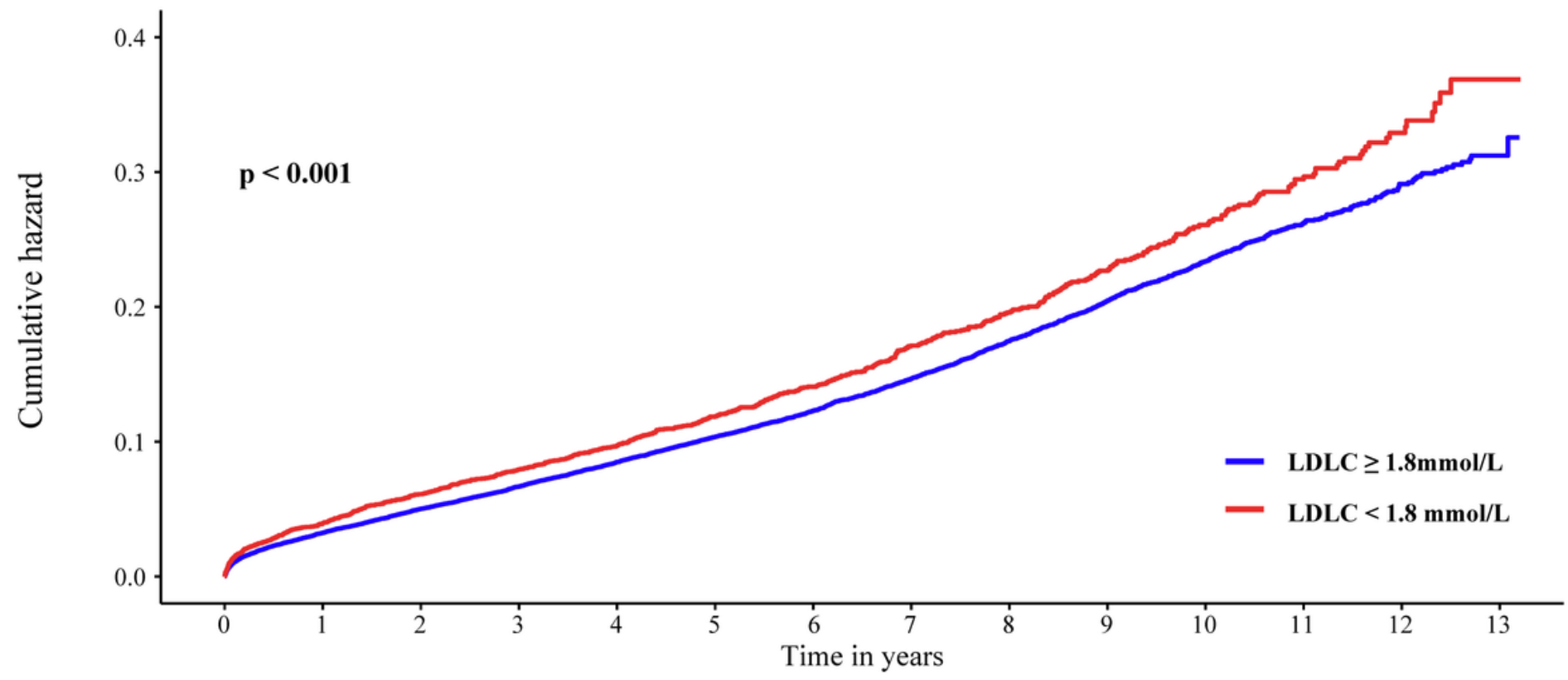

Number at risk

\begin{tabular}{|c|c|c|c|c|c|c|c|c|c|c|c|c|c|c|}
\hline $\mathrm{LDLC} \geq 1.8 \mathrm{mmol} / \mathrm{L}$ & 36366 & 35209 & 32374 & 27207 & 22431 & 18397 & 14720 & 11063 & 8200 & 5901 & 3882 & 2176 & 1011 & 141 \\
\hline $\mathrm{LDLC}<1.8 \mathrm{mmol} / \mathrm{L}$ & 4863 & 4675 & 4422 & 4068 & 3702 & 3053 & 2384 & 1856 & 1419 & 1004 & 703 & 516 & 235 & 30 \\
\hline & 0 & 1 & 2 & 3 & 4 & 5 & $\begin{array}{c}6 \\
\text { Time }\end{array}$ & $\begin{array}{c}7 \\
\text { years }\end{array}$ & 8 & 9 & 10 & 11 & 12 & 13 \\
\hline
\end{tabular}




\section{Figure 3}

Cumulative incidence of all-cause death for $L D L-C<1.8 \mathrm{mmol} / \mathrm{L}$ group vs. $L D L-C \geq 1.8 \mathrm{mmol} / \mathrm{L}$ group in CAD patients.

\section{HR(95\%CI) for long-term all-cause mortality}

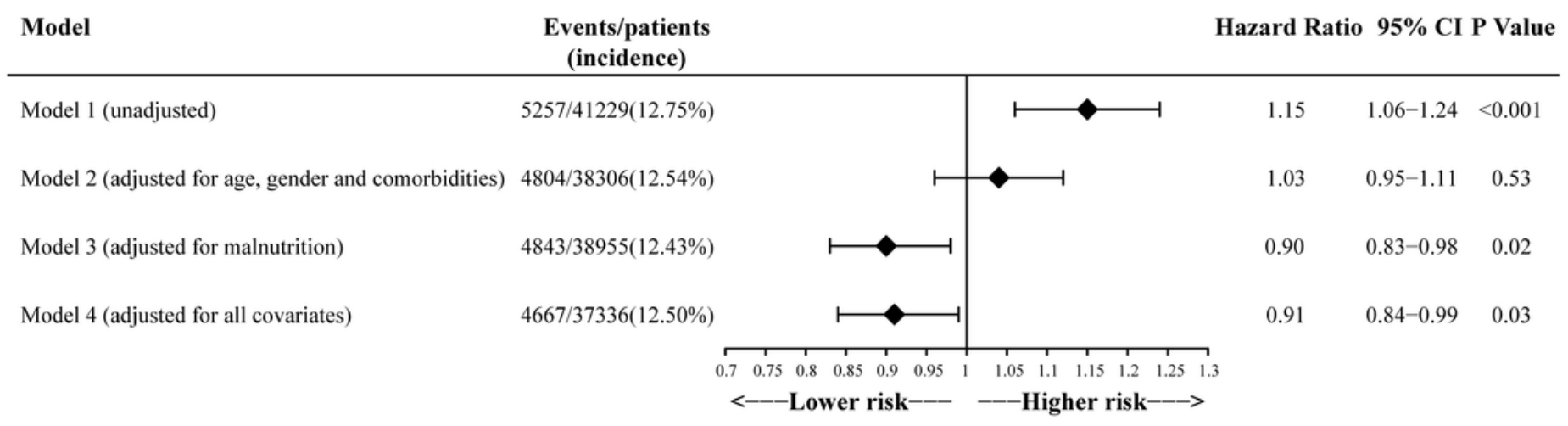

\section{Figure 4}

Unadjusted and adjusted HRs and $95 \%$ Cls for the primary end point (long-term all-cause mortality) of LDL-C $<1.8 \mathrm{mmol} / \mathrm{L}$ group vs. $\mathrm{LDL}-\mathrm{C} \geq 1.8 \mathrm{mmol} / \mathrm{L}$ group in CAD patients. Model 1: Unadjusted model. Model 2: Adjusted for age $\geq 75$ years, sex and comorbidities including AMI, diabetes mellitus, hypertension, atrial fibrillation, COPD, CHF, CKD and anemia. Model 3: Adjusted for malnutrition. Model 4: Adjusted for all covariates: age $\geq 75$ years, sex and comorbidities including AMI, diabetes mellitus, hypertension, atrial fibrillation, COPD, CHF, CKD, anemia and malnutrition. 